\title{
Linfoma cutâneo não-epiteliotrópico em cão
}

\section{[Cutaneous nonepitheliotropic lymphoma in a dog]}

\section{"Relato de Caso/Case Report"}

\author{
Saulo Romero Felix Gonçalves ${ }^{1 *}$, Sandra Maria Torres ${ }^{1}$, Amanda de Deus Ferreira Alves ${ }^{1}$, \\ Melina Barreto Gomes da Silva ${ }^{1}$, Andréa Alice da Fonseca Oliveira ${ }^{1}$, \\ Valdemiro Amaro da Silva Júnior ${ }^{1}$, Stephanie Caroline Gueiros Silva ${ }^{2}$, \\ Márcia Bersane Araújo de Medeiros Torres ${ }^{2}$
}

\begin{abstract}
${ }^{1}$ Departamento de Medicina Veterinária, Universidade Federal Rural de Pernambuco, Recife-PE, Brasil. ${ }^{2}$ Laboratório de Anatomia e Patologia Animal, Universidade Federal Rural de Pernambuco, Unidade Acadêmica de Garanhuns, Garanhuns - PE, Brasil.

*Autor para correspondência/Corresponding author: E-mail: saulofelix.vet@gmail.com
\end{abstract}

\section{Resumo}

Objetivou-se relatar um caso de linfoma cutâneo não-epiteliotrópico em canino, destacando-se os aspectos clínicos e patológicos da neoplasia. Foi atendido no Hospital Veterinário da Universidade Federal Rural de Pernambuco (UFRPE), um cão de raça Shih-Tzu, macho, não castrado, com sete anos e pesando aproximadamente $5,3 \mathrm{~kg}$. O paciente apresentava neoformação ulcerada, eritematosa e com secreção purulenta em formato de anel em região do cotovelo no membro anterior direito e nódulo ulcerado e com presença de crostas em região do membro posterior esquerdo. Foram realizadas análises hematológicas, bioquímica sérica, citologia aspirativa por agulha fina e biópsia para análise histopatológica. No hemograma, detectou-se anemia normocítica normocrômica com leucocitose e neutrofilia relativa e absoluta. Ao exame bioquímico, observouse a presença de hiperproteinemia e hiperglobulinemia. A citologia demonstrou alta celularidade, com presença de células multinucleadas e figura de mitose. No exame histopatológico foi observada acentuada celularidade composta por células redondas, infiltrados neoplásicos dispostos em cordões localizados na derme profunda e tecido subcutâneo, sendo então, estabelecido o diagnóstico de linfoma cutâneo não epiteliotrópico. Por se tratar de uma enfermidade sistêmica, o linfoma torna-se uma neoplasia de difícil tratamento. O diagnóstico pela citologia aspirativa juntamente com o exame histopatológico e sinais clínicos foram essenciais para o diagnóstico de Linfoma não-epiteliotrópico no presente relato.
\end{abstract}

Palavras-chave: canino; doença linfoproliferativa; epiderme; neoplasia.

\begin{abstract}
The objective of this study was to report a case of nonepitheliotropic cutaneous lymphoma in a dog, highlighting the clinical and pathological aspects of this neoplasia. A seven-year-old intact male Shih-Tzu dog, weighing approximately $5.3 \mathrm{~kg}$ was seen at the Veterinary Hospital of the Federal Rural University of Pernambuco (UFRPE). The patient presented an ulcerated, erythematous neoformation with purulent secretion in a ring-shaped region of the elbow in the right anterior limb and ulcerated nodule with crusts in the left hind limb. Hematological analysis, serum biochemistry, fine needle aspiration cytology, and biopsy for histopathological analysis were performed. Normocytic normochromic anemia was detected with leukocytosis and relative and absolute neutrophilia on blood count. Hyperproteinemia and hyperglobulinemia was observed on the biochemical exam. Cytology showed a high cellularity, with the presence of multinucleated cells and mitosis. Histopathological examination showed a marked cellularity composed of round cells, neoplastic infiltrates arranged in cords located in the deep dermis and subcutaneous tissue, and the diagnosis of nonepitheliotropic cutaneous lymphoma was established. Because it is a systemic disease, lymphoma becomes a difficult neoplasm to treat. Diagnosis by aspiration cytology together with histopathological examination and clinical signs were essential for the diagnosis of non-epitheliotropic lymphoma in the present report.
\end{abstract}

Keywords: canine; lymphoproliferative disorders; epidermis; neoplasia. 


\section{Introdução}

Dentre as neoplasias que mais acometem os cães, o linfoma se encontra, entre as mais frequentes, representando cerca de 7 a $24 \%$ de todas as neoplasias e corresponde aproximadamente a $83 \%$ das de origem hematopoiética (Teske, 1994; Morris e Dobson, 2001; Vail e Young, 2007; Raskin, 2011). O linfoma geralmente se inicia em órgãos linfoides, tais como linfonodos, baço e medula óssea, porém pode ocorrer em qualquer tecido, e deste modo pode ser classificado anatomicamente em multicêntrico, mediastínico, alimentar e cutâneo (Jacobs et al., 2002; Raskin, 2011; Dagli, 2015).

O Linfoma Cutâneo (LC) é considerado uma forma rara do linfoma canino, representando somente $1 \%$ das neoplasias cutâneas em cães. Caracteriza-se pela infiltração de linfócitos T ou B, na derme, epiderme ou tecidos anexos, sendo histologicamente classificados em linfoma cutâneo epiteliotrópico (LCE) e não epiteliotrópico (LCNE). Um possível fator predisponente considerado para o aparecimento do linfoma cutâneo é a inflamação crônica da pele. A ativação e proliferação crônica de linfócitos podem ser estimuladas pelo contato com antígenos do ambiente e/ou anormalidades na função das células de Langherans e sugere-se que a proliferação desses linfócitos ativados possa ser a origem do linfoma cutâneo (Fontaine et al., 2009).

A forma clínica do LC é altamente pleomórfica e pode mimetizar diversas dermatopatias, desta forma grupos heterogêneos de apresentações clínicas são evidenciadas (Dalek et al., 2008; Fontaine et al., 2009).

O LCNE é descrito com menos frequência que o LCE e histologicamente se caracteriza por uma infiltração dérmica e subcutânea difusa de linfócitos $\mathrm{T}$ ou $\mathrm{B}$. Lesões nodulares, firmes, não pruriginosas e ulceradas são comuns, com progressão rápida, resposta à terapia incipiente $\mathrm{e}$ menor taxa de sobrevivência (Moore e Olivry, 1994).

O diagnóstico definitivo do LC se baseia na análise histopatológica (Vail, 2004), entretanto a citologia aspirativa por agulha fina (CAAF) tem demonstrado ótimos resultados no seu diagnóstico, sendo uma técnica de baixo custo e de fácil execução (Ganguly et al., 2013).

Os principais diagnósticos diferenciais do LC Canino são os distúrbios dermatológicos (alérgicos, infecciosos e imunomediados) e outras neoplasias cutâneas (Vail e Young, 2007; Daleck et al., 2008; Dagli, 2015).

Diante do exposto, objetivou-se relatar um caso clínico de linfoma cutâneo não-epiteliotrópico em um canino, destacando-se os aspectos clínicos e patológicos da neoplasia.

\section{Descrição do Caso}

Foi atendido no Hospital Veterinário da UFRPE (campus Recife), um cão da raça Shih-Tzu, macho, não castrado, com sete anos e pesando aproximadamente $5,3 \mathrm{Kg}$, apresentando um nódulo em região do cotovelo no membro anterior direito e outro em região lateral no membro posterior esquerdo. Segundo o tutor, os nódulos apareceram há cerca de um mês e permaneceram evoluindo. $\mathrm{O}$ animal já havia sido previamente atendido em clínica particular, local em que foi instituído o tratamento com anti-inflamatório e antibiótico; porém como não houve melhora, o tutor decidiu encaminhá-lo ao referido hospital.

Ao exame clínico, o animal se encontrava em estação, alerta, com mucosas normocoradas, temperatura retal de $37,9^{\circ} \mathrm{C}$, linfonodos sem alteração, e foi constatada a presença de duas neoformações, uma ulcerada, com secreção purulenta e eritematosa em formato de anel em região de cotovelo medindo aproximadamente $7 \mathrm{~cm}$ de diâmetro (Figura 1A) e outra ulcerada e com presença de crostas medindo aproximadamente $1 \mathrm{~cm}$ de diâmetro, localizada em membro posterior esquerdo (Figura 1B). Outras neoformações não ulceradas, não alopécicas de consistência fibroelástica e móvel também foram detectadas medindo aproximadamente $0,5 \mathrm{~cm}$ em região de flanco e cabeça.

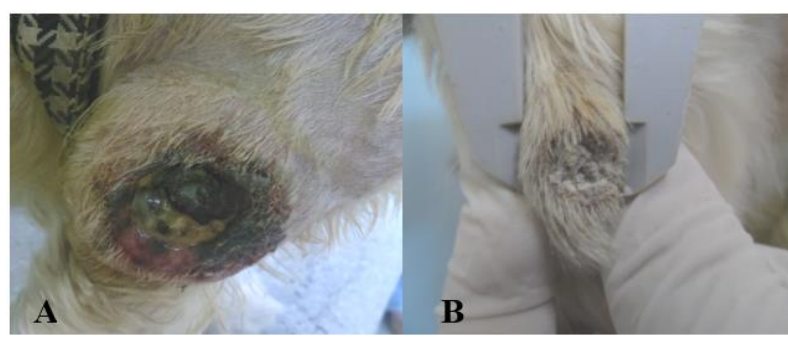

Figura 1. Neoformações na pele de cão da raça Shih-Tzu. (A) Região do Cotovelo. Neoformação ulcerada e eritematosa em formato de anel com presença de secreção purulenta. (B) Membro posterior esquerdo. Neoformação ulcerada e com presença de crostas.

Diante do caso, foram solicitadas análises hematológicas, bioquímica sérica (ureia, creatinina, 
alanina aminotransferase (ALT), fosfatase alcalina (FA), gama glutamiltransferase (GGT), proteína total, albumina, globulina e cálcio), CAAF e biópsia incisional para análise histopatológica das neoformações localizadas em região de cotovelo e em membro posterior esquerdo.

\section{Resultados}

Os resultados das análises hematológicas e bioquímica sérica estão dispostos nas Tabelas $1 \mathrm{e}$ 2.

Tabela 1. Análise hematológica do canino da raça ShihTzu.

\begin{tabular}{lll}
\hline \multicolumn{1}{c}{ Hemograma } & \multicolumn{1}{c}{ Resultado } & \multicolumn{1}{c}{$\begin{array}{c}\text { Valores de } \\
\text { Referência Cão* }\end{array}$} \\
\hline Hemácias & $3,85.10^{6} / \mathrm{mL}$ & 5,5 a $8,5.10^{6} / \mathrm{mL}$ \\
Hemoglobina & $8,6 \mathrm{~g} / \mathrm{dL}$ & 12,0 a $18,0 \mathrm{~g} / \mathrm{dL}$ \\
Hematócrito & $23,0(\mathrm{vg}) \%$ & 37,0 a $55,0(\mathrm{vg}) \%$ \\
VCM & $59,7 \mathrm{fL}$ & 60,0 a $77,0 \mathrm{fL}$ \\
CHCM & $37,4 \%$ & 32 a $36 \%$ \\
PT & $8,2 \mathrm{~g} / \mathrm{dL}$ & 6,0 a $8,0 \mathrm{~g} / \mathrm{dL}$ \\
RDW & $12,6 \%$ & 13,8 a $18,0 \%$ \\
Plaquetas & $200.10^{3} / \mu \mathrm{L}$ & 200 a $500.10^{3} / \mu \mathrm{L}$ \\
Leucócitos & $6,6.10^{3} / \mathrm{mL}$ & $6 \mathrm{a} 17.10^{3} / \mathrm{mL}$ \\
\hline
\end{tabular}

"Fonte: Manual de Patologia Clínica Veterinária - UFSM, 2009.

Tabela 2. Resultados dos valores bioquímicos do canino da raça Shih-Tzu.

\begin{tabular}{lll}
\hline \multicolumn{1}{c}{ Bioquímico } & \multicolumn{1}{c}{ Valores } & \multicolumn{1}{c}{ Referências $^{*}$} \\
\hline Ureia & $36,0 \mathrm{mg} / \mathrm{dL}$ & 21,4 a $59,92 \mathrm{mg} / \mathrm{dL}$ \\
Creatinina & $0,7 \mathrm{mg} / \mathrm{dL}$ & 05 a $1,5 \mathrm{mg} / \mathrm{dL}$ \\
ALT & $24,0 \mathrm{UI} / \mathrm{L}$ & 21,0 a $86,0 \mathrm{UI} / \mathrm{L}$ \\
FA & $28,0 \mathrm{UI} / \mathrm{L}$ & 20,0 a $156,0 \mathrm{UI} / \mathrm{L}$ \\
GGT & $1,3 \mathrm{UI} / \mathrm{L}$ & 1,2 a $6,4 \mathrm{UI} / \mathrm{L}$ \\
Proteína Total & $7,9 \mathrm{~g} / \mathrm{dL}$ & 5,4 a $7,1 \mathrm{~g} / \mathrm{dL}$ \\
Albumina & $1,5 \mathrm{~g} / \mathrm{dL}$ & 2,6 a $3,3 \mathrm{~g} / \mathrm{dL}$ \\
Globulina & $6,4 \mathrm{~g} / \mathrm{dL}$ & 2,7 a $4,4 \mathrm{~g} / \mathrm{dL}$ \\
Cálcio & $10,2 \mathrm{mg} / \mathrm{dL}$ & 9,0 a $11,3 \mathrm{mg} / \mathrm{dL}$ \\
\hline
\end{tabular}

*Fonte: Manual de Patologia Clínica Veterinária - UFSM, 2009.

As neoformações em região de cotovelo e em membro posterior esquerdo do paciente em questão foram submetidas à CAAF sendo a amostra citológica caracterizada por apresentar alta celularidade com predomínio de células redondas organizadas isoladamente, citoplasma escasso bem delimitado de coloração acidofílica, núcleos arredondados (por vezes ocupando todo $\mathrm{o}$ citoplasma) com cromatina rendilhada à grosseira com grandes nucléolos evidentes. As células apresentavam alto grau de anisocitose, anisocariose, núcleos clivados, cariomegalia, figuras de mitose e células multinucleadas. No fundo de lâmina predominaram conteúdo amorfo, moderados neutrófilos e eritrócitos e a presença de corpúsculos linfoglandulares, sendo a neoplasia classificada em linfoma anaplásico de alto grau (Figura 2).

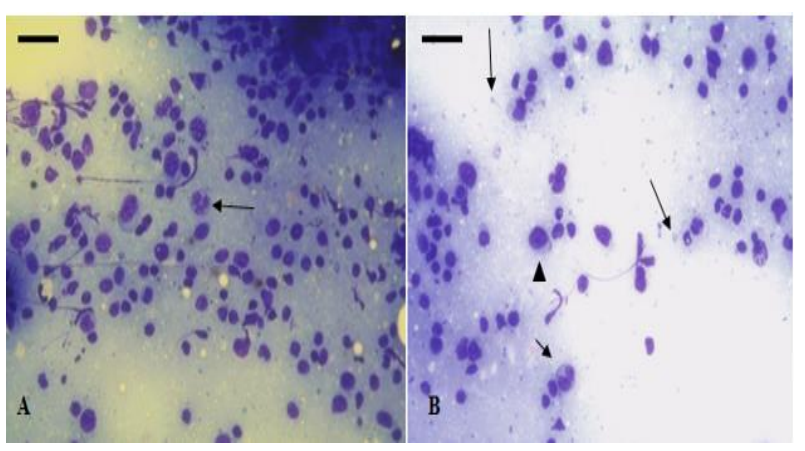

Figura 2. Fotomicrografia de CAAF em canino Shih-Tzu. Linfoma de alto grau anaplásico. (A) Alta celularidade; notar célula multinucleada (seta longa). (B) Célula com núcleo clivado (seta). Presença de corpúsculos linfoglandulares (seta longa) e cariomegalia (cabeça de seta). (A) e (B) Acentuado pleomorfismo celular. Panótico rápido $(40 \mathrm{x}$, Barra $=50 \mu \mathrm{m})$.

A avaliação histopatológica revelou epiderme ulcerada com área localmente extensa de necrose, associada a colônias de bactérias e infiltrado inflamatório neutrofílico. Também foi constatada acentuada celularidade neoplásica composta por células redondas arranjadas em manto não encapsulada e infiltradas, dispostas em cordões localizadas na derme profunda e tecido subcutâneo. A derme superficial não apresentava infiltração de células neoplásicas (zona de Grenz) ou invasão de estruturas anexas e as fibras de colágenos se encontravam frouxas e rarefeitas. As células neoplásicas apresentavam escasso citoplasma bem delimitado, levemente basofílico, contendo núcleo central de formato indentado e cromatina rendilhada contendo até três nucléolos proeminentes, além de acentuada anisocitose e anisocariose. Foram observadas seis figuras de mitoses atípicas em dez campos de maior aumento (40x) além de células multinucleadas (Figuras 3A a 3B). O linfoma foi caracterizado pela avaliação histomorfológica como linfoma nãoepiteliotrópico. 


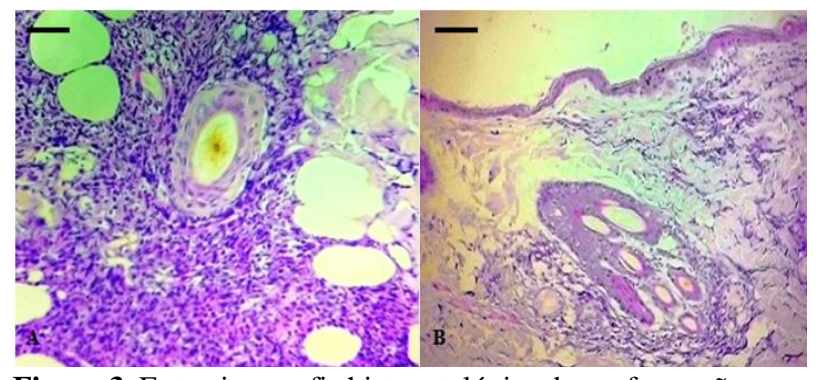

Figura 3. Fotomicrografia histopatológica de neoformação em canino Shih-Tzu. Linfoma não epiteliotrópico. (A) Observar anexo cutâneo sem invasão de células neoplásicas, células dispostas em manto não encapsulado e tecido subcutâneo com infiltração de células neoplásicas com escasso citoplasma e alto pleomorfismo. (B) Infiltrado neoplásico disposto em cordões, em epitélio. (HE, 20X, Barra $=20 \mu \mathrm{m}$ ).

\section{Discussão}

O linfoma é uma neoplasia caracterizada por ausência de predisposição racial (Vail, 2004), sendo pouco relatada em animais de pequeno porte (Nelson e Couto, 2010; Raskin, 2011). Em estudo retrospectivo de linfoma canino realizado por Moreno et al. (2007a) na região norte do Paraná, durante o período de 1990 a 2004, constatou-se uma maior ocorrência da neoplasia em cães das raças Poodle, Tekel e Pincher. No presente relato tratava-se de um cão da raça Shih-Tzu, diferindo do relatado por alguns autores (Nelson e Couto, 2010; Raskin, 2011), porém a questão racial é muito variável considerando a diversidade e predominância de algumas raças nas diferentes regiões.

$\mathrm{O}$ animal residia em zona rural da cidade de Recife/PE, porém não foram obtidas outras informações epidemiológicas pelo tutor que permitissem estabelecer uma relação da neoplasia com possíveis fatores de risco, como foi demonstrada no estudo de Zanini (2013) sobre a exposição de cães a poluente de áreas urbanas com grandes tráfegos de veículos nas cidades como fatores de risco para o desenvolvimento do linfoma. Mas, segundo o mesmo autor, é sabido que o contato do animal com substâncias químicas como agrotóxicos dentre alguns pesticidas, é fator de risco para o desenvolvimento do linfoma canino, assim como o convívio com pessoas fumantes, pois o tabagismo é outro fator que colabora para o desenvolvimento da neoplasia.

A apresentação macroscópica da neoplasia em formato de anel observada neste caso, também consiste em um tipo de lesão típica para linfomas cutâneos (Nelson e Couto, 2010).

Em relação aos exames complementares solicitados neste relato, o hemograma revelou uma anemia normocítica normocrômica, estando de acordo com alguns autores (Moreno et al., 2007b), sendo um achado comum em pacientes com linfoma devido à cronicidade da doença, desordem metabólica, redução de meia-vida dos eritrócitos e diminuição da resposta da medula óssea (Fighera et al., 2002), sendo relatada como a alteração hematológica de maior frequência no estudo de Neuwald et al. (2014) ao demonstrarem que a anemia estava presente em $57 \%$ (17/30) dos animais avaliados. No exame bioquímico, a discreta hiperproteinemia com hiperglobulinemia são significativas, pois são componentes da síndrome paraneoplásica, de ocorrência frequente no linfoma e em outras enfermidades hematopoiéticas (Vail, 2004; Dalek et al., 2008), concordando com Cardoso et al. (2004) que citaram a presença de hiperglobulinemia em 20,37\% dos casos de linfoma analisados

$\mathrm{Na}$ CAAF se observou a presença de corpúsculos linfoglandulares, que são encontrados rotineiramente em linfomas devido à ruptura de linfócitos pela sua fragilidade e imaturidade, entretanto não é considerado um padrão conclusivo para o diagnóstico de linfoma (Dalek et al., 2008; Nelson e Couto, 2010).

As características histopatológicas observadas no linfoma do presente relato foram às mesmas observadas por De Bosschere (2008), que também relatou a presença de células com binucleação, elevada anisocitose e polimorfismo nuclear. $\mathrm{O}$ fato de existir acentuado pleomorfismo celular com células pequenas e grandes, dificulta o diagnóstico morfológico (Goldschmidt e Hendrick, 2002), recomendando-se quando possível, a utilização da técnica de imunohistoquímica para obtenção do imunofenótipo das células neoplásicas, permitindo classificá-las como células $\mathrm{T}$ e/ou B (Raskin, 2011) e possibilitando deste modo um adequado prognóstico, entretanto neste estudo não foi possível realizá-la. A disposição celular em formato de cordões encontrado no caso é um achado comum na forma clássica do linfoma não-epiteliotrópico canino (Hendrick, 2017).

A conformação dos núcleos com formatos variados, levemente basofílico com nucléolos proeminentes, foi observado em um relato de linfoma não-epiteliotrópico em cão de raça Golden Retriever (De Bosschere, 2008) assim como a epiderme com extensa área de necrose.

Neste tipo de linfoma cutâneo, foi encontrada alta atividade mitótica, sendo observadas seis figuras de mitoses atípicas em dez 
campos, achado que corrobora com outros autores (Goldschmidt e Hendrick, 2002; De Bosschere, 2008).

No presente relato o desfecho do caso culminou com o óbito do animal, não permitindo deste modo a realização de terapêutica adequada. O diagnóstico precoce, o que não ocorreu neste caso uma vez que o paciente já havia recebido atendimento anteriormente, assim como a terapêutica instituída no início colaboram de forma significativa no prognóstico e período de sobrevida do paciente.

\section{Conclusão}

Com base no diagnóstico de linfoma canino não-epiteliotrópico relatado no presente trabalho ressalta-se a importância da aplicação de técnicas diagnósticas, representadas neste caso pela análise hematológica, citologia aspirativa, histopatologia e sinais clínicos, que de forma associada atuaram como norteadores na obtenção de um diagnóstico fidedigno, o que propicia ao médico veterinário a tomada de decisões de forma adequada.

\section{Conflito de Interesse}

Os autores declaram não existir conflito de interesse.

\section{Referências}

Cardoso, M.J.L.; Machado, L.H.A.; Moutinho, F.Q.; Padovani, C.R. Linfoma canino achados clínico-patológicos. Archives of Veterinary Science, 9(2): 25-29, 2004.

Dagli, M.L.Z. Introdução a oncologia veterinária. In: Jericó, M.M.; Kogika, M.M.; Andrade Neto, J.P. Tratado de medicina interna de cães e gatos. $1^{\text {a }}$ ed. Rio de Janeiro: Roca, 2015. p.478.

Daleck, C.R.; De Nardi, A.B.; Rodaski, S. Oncologia em cães e gatos. $1^{\text {a }}$ ed. São Paulo: Roca, 2008. 482p.

De Bosschere, H.; Declercq, J. Cutaneous nonepitheliotropic B-cell lymphoma in a Golden retriever. Vlaams Diergeneeskundig Tijdschrift, 77(315): $\mathrm{p}$ 315-318, 2008.

Fighera, R.A.; Souza, T.M.; Barros, C.S.L. Linfossarcoma em cães. Ciência Rural, 32(5): 895-899, 2002.

Fontaine, J.; Bovens, C.; Bettenay, S.; Mueller, R.S. Canine cutaneous epitheliotropic T-cell lymphoma: a review. Veterinary and Comparative Oncology, 7(1): 1-14, 2009.
Ganguly, B., Das, U., Das, K. Canine transmissible venereal tumour: a review. Veterinary and Comparative Oncology, 11(4): 1-12, 2013.

Goldschmidt, M.H.; Hendrick, M.J. Tumors of the skin and soft tissues. In: Meuten, D.J. Tumors in Domestic Animals. $4^{\text {th }}$. Iowa: State Press, 2002. p. 45-118.

Hendrick, M.J. Mesenchymal tumors of the skin and soft tissues. In. Meuten, D.J. Tumors in domestic animals. $5^{\text {th }}$. Wiley Blackwell: Raleigh, 2017. p.172-173.

Jacobs, R.M.; Messick, J.B.; Valli, V.E. Tumors of the hemolymphatic system. In: Meuten, D.J. Tumors in domestic animals. $4^{\text {th }}$. Iowa: Iowa State Press, 2002. p. 119-198.

Moore, P.F.; Olivry, T. Cutaneous Lymphomas in Companion Animals. Clinics in Dermatology, 12(4): 499-505, 1994.

Moreno, K.; Frederico, A.P.; Bracarense, R.L. Estudo retrospectivo de linfoma canino no período de 1990 - 2004 na Região Norte do Paraná. Brazilian Journal of Veterinary Research and Animal Science, 44(suplemento): 46-52, $2007 \mathrm{a}$.

Moreno, K.; Frederico, A.P.; Bracarense, R.L. Linfoma canino de células $\mathrm{T}$ : aspectos epidemiológicos, clínicos e morfológicos de 38 casos. Brazilian Journal of Veterinary Research and Animal Science, 44(suplemento): 103-110, $2007 \mathrm{~b}$.

Morris, J.; Dobson, J. Introduction. In: __ . Small animal oncology. $1^{\text {st }}$. Blackwell Science: Oxford, 2001. p. 1-3.

Nelson, R.W.; Couto, C.G. Linfoma no cão e no gato. In: _. Medicina interna de pequenos animais. $4^{\mathrm{a}}$ ed. Rio de Janeiro: Elsevier, 2010. p. 1176-1188.

Neuwald, E.B.; Teixeira, L.V.; Conrado, F.O.; Silva, M.O.D.; Hlavac, N.R.C.; González, F.H.D. Epidemiological, clinical and immunohistochemical aspects of canine lymphoma in the region of Porto Alegre, Brazil. Pesquisa Veterinária Brasileira, 34(4): 349-354, 2014.

Raskin, R.E. Sistema linfóide. In: Raskin, R.E.; Meyer, D.J. Citologia clínica de cães e gatos: atlas colorido e guia de interpretação. $2^{\mathrm{a}}$ ed Rio de Janeiro: Elsevier, 2011. p. 79-112.

Teske, T. Malignant lymphomas in dogs: a review with reference to non-Hodgkin lymphoma in man. The Veterinary Quarterly, 16(4): 209-219, 1994. 
Vail, D.M. Tumores hematopoiéticos. In: Ettinger, S.J.; Feldman, E.C. Tratado de medicina interna veterinária. $5^{\mathrm{a}}$ ed. Rio de Janeiro: Guanabara Koogan, 2004. p. 538-544.

Vail, D.M.; Young, K.M. Hematopoietic tumors. In: Withrow, S.J.; Vail, D.M. Small animal clinical oncology. $4^{\text {th }}$. Missouri: Saunders, 2007. p.699-784.

Zanini, D.A.; Kimura, K.C.; Nishiya, A.T.; Ubukata, R.; Leandro, R.M.; Brito, C.P.;
Trombetti, M.; Lagoa, A.C.; Macedo, T.R.; Rodrigues, L.C.S.; Rosendo, J.A.S.; Arndt, H.L.; Dias, R.A.; Dagli, M.L.Z. Environmental risk factors related to the development of canine non-Hodgkin's lymphoma/Fatores de risco ambientais relacionados ao desenvolvimento do linfoma não Hodgkin canino. Ciência Rural, 43(7): 1302-1308, 2013. 